\title{
Infrared thermal imaging in studies of wild animals
}

\author{
Justyna Cilulko • Pawel Janiszewski • \\ Marek Bogdaszewski • Eliza Szczygielska
}

Received: 17 August 2012 /Revised: 13 December 2012 / Accepted: 17 December 2012 /Published online: 30 December 2012

(C) The Author(s) 2012. This article is published with open access at Springerlink.com

\begin{abstract}
Thermography is an imaging method which registers infrared waves in the electromagnetic spectrum that are emitted by all objects on the Earth. The state and properties of the studied objects and organisms can be evaluated by analyzing images of temperature distribution on their surface. Thermography has numerous practical applications, including in construction, industry, and the military and civil services. In natural sciences, thermal imaging techniques support safe and non-invasive measurements and the acquisition of results that cannot be obtained by any other method. Infrared thermography also creates a wide range of applications for human and veterinary medicine, ecology, zoology, and other natural sciences. Thermal imaging equipment is used to detect injuries, inflammations, and infectious diseases to control reproduction (detection of estrus and pregnancy, determination of male fertility) and lactation processes. The discussed method is applied to investigate thermoregulation in animals, to analyze the effect of environmental factors on animal behavior, to localize individuals and their habitats, and to determine the size of wildlife populations. Despite a wide range of practical applications, thermal imaging has a number of limitations which should be taken into account in studies that rely on infrared thermography techniques.
\end{abstract}

Keywords Thermography · Non-invasive tests · Estimation of population size $\cdot$ Detection of animals

Communicated by C. Gortázar

J. Cilulko $(\bowtie) \cdot$ P. Janiszewski

Department of Fur-Bearing Animal Breeding and Game Management,

Faculty of Animal Bioengineering, University of Warmia and Mazury

in Olsztyn, Oczapowskiego 5,

10-719 Olsztyn, Poland

e-mail: justyna.cilulko@uwm.edu.pl

M. Bogdaszewski • E. Szczygielska

Research Station of the Institute of Parasitology,

Polish Academy of Sciences, Kosewo Górne, Poland

\section{Introduction}

Infrared thermography (IRT) is a safe and non-invasive method for remote sensing of temperature distribution patterns on the surface of the body. It has a variety of practical applications in industry, construction, police, rescue operations, border patrol, human and veterinary medicine, animal husbandry, biology, and ecology (McCafferty 2007). In studies of animals, thermal imaging cameras are used remotely, and the observed subject does not have to be restricted or sedated, which significantly reduces stress levels. IRT is a useful tool in studies of livestock (without compromising their welfare), wild animals (detection of animal habitats, estimation of the population size), and zoo animals (Lavers et al. 2005). In human and veterinary medicine, thermal imaging cameras are applied to measure body surface temperature which is a product of the temperature of internal tissues and the outer surface of the body. Physiological processes affect the temperature of internal tissues by increasing or decreasing blood flow. For instance, heat generated during the inflammatory process is transferred to the adjacent tissues (including skin) via enhanced capillary blood flow and is dissipated as infrared energy (Knizkova et al. 2007). A healthy organism is characterized by a balanced distribution of temperature between different parts of the body. The same anatomical parts can be compared to identify warmer spots, and the causes of thermal deregulation can be determined based on our knowledge of a given species (Bowers et al. 2009). In veterinary diagnostics of farm and wild animals, thermal imaging is used to determine the causes of lameness, injuries, and inflammations of the locomotor system; to diagnose infectious diseases, estrus, and pregnancy; and to control animal welfare and stress levels. Animal habitats and their population size can be identified with the use of remote sensing techniques if sufficient differences in temperature exist between the studied object and its surroundings. 
This article discusses practical applications of thermography in studies of wild animal populations, the limitations of thermal imaging, and possible ways to eliminate measurement errors.

\section{Thermography applications in studies of wild animals}

\section{Disease diagnosis}

The use of thermography for diagnosing contagious diseases and infections in farm animals has been studied extensively for years. Positive research outcomes prompted scientists to investigate the effectiveness of thermographic methods in diagnosing non-invasive diseases in wild animals.

Dunbar et al. (2009) used infrared thermography to detect temperature changes in mule deer (Odocoileus hemionus) infected with foot-and-mouth disease. A considerable rise in temperature was observed in thermograms as early as 2 days before the occurrence of the first disease symptoms.

Arenas et al. (2002) applied infrared thermal imaging to diagnose sarcoptic mange in the wild Spanish ibex (Capra pyrenaica). Infrared thermography was performed under natural conditions, and the results were compared with those obtained with the use of conventional binoculars. Following the observations, the animals were sacrificed, the distance from the thermograph to the animals was measured, and skin samples were collected for analysis. The use of binoculars was a preferred technique for the tele-diagnosis of sarcoptic mange in the Spanish ibex, in particular over distances greater than $100 \mathrm{~m}$.

Dunbar and MacCarthy (2006) used IRT to detect the signs of rabies infection in raccoons (Procyon lotor). The cited authors found that infrared thermography supported the detection of animals at the infectious stage and those showing clinical signs of rabies, based on nose temperature data.

\section{Control of reproductive processes}

Hilsberg-Merz (2008) relied on IRT to diagnose ovulation in Asian elephants and black rhinoceros. The author observed increased temperature levels in the area of the female reproductive organs, and the behavior of male individuals confirmed suspicions of ovulation. Similar results were noted in a female rhinoceros, but thermographic examinations of the vulvar area are difficult to perform in the species due to complex position of the tail. According to Hilsberg-Merz, thermal imaging is a highly promising tool for controlling the reproductive cycle in animals where other high-precision methods are difficult to perform.

Hilsberg (1998) reported on the use of IRT to detect pregnancy in the black rhinoceros. According to the above author, thermal imaging is effective in diagnosing late stages of pregnancy in the species (and similar taxa) if a number of conditions are met, including adequate preparation of the animal for the examination. Durrant et al. (2006) evaluated the suitability of infrared thermography to detect pregnancy in giant pandas, using the domestic dog as a model for comparative purposes. Pregnancy and pseudopregnancy were successfully detected in giant pandas by the tested technique, whereas further research is needed to find out whether thermal imaging can be applied for pregnancy diagnosis in bitches.

\section{Thermoregulation}

Speakman and Ward (1998) described a study which investigated heat transfer under various ambient temperatures (from -25 to $33{ }^{\circ} \mathrm{C}$ ) in three fox species: the red fox (Vulpes vulpes), the Arctic fox (Alopex lagopus), and the kit fox (Vulpes macrotis) native to the southern parts of North America and Middle America. Thermal images revealed that the nose, lower legs, paws, and the front of the ears were important thermoregulatory surfaces in all fox species, while the back of the ears and the face played a key role only in $V$. vulpes and $V$. macrotis. Arctic foxes are adapted to live in cold climates - the portion of their body surface involved in heat loss control is reduced, compared with the other species (Arctic foxes - $21 \%$, red foxes and kit foxes 33 to $38 \%$ ). In kit foxes adapted to warm climates, the nose is the only part of the body (in all three species) that is cooler than ambient temperature. With the use of infrared thermography, the cited authors were able to identify the key thermoregulatory mechanisms in three animal species living in different climatic conditions.

Kuhn and Meyer (2009) studied body surface temperatures in two otter species, the Eurasian otter (Lutra lutra) and the tropical giant otter (Pteronura brasiliensis), based on infrared thermography. They found that Eurasian otters used their feet to dissipate excess heat, whereas giant otters lost heat through the entire body surface, including the tail. In both species, specific regions involved in thermoregulation were located on the head.

Klir et al. (1990), who analyzed thermoregulation in the Mongolian gerbil (Meriones unguiculatus), reported that this species has not developed any specific thermoregulatory surface areas to regulate heat exchange with the environment, and therefore its control of body surface temperature is limited. In Mongolian gerbils, the thermoneutral zone is between 28 and $32{ }^{\circ} \mathrm{C}$, and the lower critical temperature is $-4{ }^{\circ} \mathrm{C}$. According to the cited authors, the animals use behavioral and ecological adaptive strategies to alleviate heat stress effects.

Tattersal and Cadena (2010) carried out a comprehensive study of body temperature changes in different animals with the use of thermal imaging. They described changes in bill 
temperature in the Toco toucan (Ramphastos toco) subject to the bird's activity (sleep, stress). The authors described also changes in the body temperature of young and adult hippopotamuses (Hippopotamus amphibius), with particular emphasis on the subcutaneous fat layer which provides insulation. The above authors cited numerous examples of successful applications of thermal imaging in studies of birds, mammals, reptiles, and amphibians, including in determining their thermal preferences and changes in body temperature.

Thermal imaging produced interesting results in a study of bats. Bats have fur-covered bodies, but their bare wings allow heat to be transferred to the surrounding environment. Lancaster et al. (1997) studied thermoregulation in the Egyptian fruit bat (Rousettus aegyptiacus). The authors measured wing temperature in flying bats by infrared thermography and found that it increased by less than $1{ }^{\circ} \mathrm{C}$ even if the flight lasted over $30 \mathrm{~min}$. The temperature difference between the wings and ambient air was insignificant. The above researchers concluded that wings could play an important role in thermoregulation in bats, but the results of thermographic analyses revealed that the above is due to large wing area and flight speed rather than differences in temperature between wings and ambient air during movement.

In contrast to bats, the bodies and wings of birds are well insulated. The only naked areas are the shanks and feet, and therefore, it had been suggested that they play an important role in heat dissipation. This hypothesis was later confirmed by studies of insectivorous bird species which were found to extend their feet under thermal stress to dissipate the excess heat uptake. Thermal images of starlings revealed that the feet play a key role in the above process and that other body parts characterized by high temperatures during flight are the head and the inner part of the lower surface of the wings (Speakman and Ward 1998). McCafferty et al. (1998) analyzed thermoregulation in the barn owl (Tyto alba). The authors demonstrated that the hottest regions of the body in this bird species are the lower abdomen and the facial disk. Heat loss from the head was almost double that from the body as a whole (although the facial disk accounts for only $30 \%$ of the total body surface). During flight, barn owls generated considerable amounts of heat, and similarly as in starlings, the hottest areas of their bodies were the feet and the lower surface of the wings. With the use of a thermal imaging camera, the authors found that the barn owl, which is not well adapted to the cold weather, reduces heat losses by roosting in buildings and tucking its head into its wings while sleeping. The nocturnal activity of barn owls enables them to use heat energy generated during flight for thermoregulation.

Sumbera et al. (2007) used infrared thermography to compare the patterns of body temperature changes and heat dissipation to the environment in two species of African mole rats of the same family, the social Fucomys mechowii and the solitary Heliophobus argenteocinereus. The authors demonstrated that the above method is simple, highly promising, and can be successfully applied in studies of animal biology and ecophysiology.

Analyses of animal behavior

Thermal imaging cameras are used to determine changes in the body temperature of animals exposed to various stressors during different types of behavior or physiological responses. Nakayama et al. (2005) examined changes in facial temperature in rhesus monkeys (Macaca mulatta) in threatening situations. The temperature of the nasal region decreased significantly within 10-30 s from the presentation of a potentially threatening person. The monkeys expressed their negative emotions by teeth baring and different facial expressions. The authors concluded that a decrease in nasal temperature can be a reliable and accurate indicator of a change from a neutral to a negative emotional state in nonhuman primates.

McCafferty (2007) described research on changes in blood flow of dolphins during their pursuit of tuna fish. From the beginning of the hunt, heat dissipation increased through the dorsal fin, and the temperature on the skin surface increased steadily during the pursuit, probably due to intensified blood flow in the area.

Thermographic methods are also applied to investigate energy expenditure in various types of animal behavior such as singing in birds. McCafferty (2007) cites from 2005 in which tested metabolic cost of signing and compared heat loss in singing and nonsinging birds in captivity. Thermal imaging was also used to observe interesting behavioral patterns in the giant honeybee (Apis dorsata), a wild species inhabiting the tropical climate zones of South Asia. The giant honeybee can selectively increase the temperature of its skeletal muscles to prepare for various types of physical activity, such as flight and dance, to maintain a stable temperature inside the nest, to attack enemies, put up an effective defense, and recognize mating partners. A bee's sting cannot penetrate the intruder's skin; therefore, bees resort to a different method of eliminating the enemy-they kill wasps by heating them. Bees surround the enemy by forming a tight ball around it. The temperature inside the ball reaches $45-48{ }^{\circ} \mathrm{C}$, and it is sufficient to kill a wasp within several minutes (Kastberger and Stachl 2003).

Hristov et al. (2008) described new applications of thermal infrared imaging in studies of free-ranging bats. The authors carried out observations of Brazilian free-tailed bats (Tadarida brasiliensis) that live in large colonies in the South Central USA. They used cameras with high thermal sensitivity and modern analytical software for behavioral 
observations of bats, thermoregulation analysis, and population counts. Thermal infrared imaging proved to be a valuable tool for investigating the behavior of bats in colonies, including their foraging behavior, differences between females and males, and young and adult individuals. The authors reconstructed the 3D flight trajectories and spatial distribution patterns of bats. Computer-vision algorithms were used to recognize and track flying bats, and to differentiate between them and other potentially warm objects, which allowed to estimate the total number of bats roosting in caves and foraging bats. According to the cited authors, thermal imaging is a highly effective technique which, combined with computer science and engineering, may be widely used in wildlife research and contribute to answering questions that have puzzled biologists for years.

\section{Detection of animals and estimation of population size}

Thermal imaging cameras are widely used to observe and detect wild animals and their habitats, and to estimate their population size. Temperature distributions do not have to be measured accurately, and animals appear as warm spots against a dark, cool background in the thermogram, which is sufficient to confirm their presence. The fact that such observations can be performed remotely creates a wealth of new opportunities for wildlife researchers.

Graves et al. (1972) compared the effectiveness of thermal imaging detectors with different sensitivity levels in aerial surveys of the white-tailed deer (Odocoileus virginianus) conducted at different altitudes, during different seasons of the year and on different times of the day. In areas not overgrown by thick vegetation, the animals were successfully identified from a height of $300 \mathrm{~m}$ above ground. The authors concluded that thermal imaging cameras were most effective in determining population size during both day and night when the sky was overcast, and the most satisfactory results were reported on relatively flat terrain without dense vegetation. Already 40 years ago, thermography was heralded as a promising method for surveying population growth and observing the behavior of large game animals.

Collier et al. (2007) compared the effectiveness of two methods for detecting white-tailed deer (O. virginianus) populations: thermal imagers (which detected $92.3 \%$ of the deer) and spotlight counts (which detected only $54.4 \%$ of the animals). According to Hodnett (2005), thermal imaging can be successfully applied to detect white-tailed deer in urban areas.

Garner et al. (1995) tested the efficiency of infrared thermography while surveying the populations of deer, moose, and wild turkeys. The authors compared their findings with the estimated densities of the above species. The number of deer detected with the use of infrared thermography was twice lower than initially expected, whereas moose densities were twice those estimated by untrained observers. Wild turkeys in flocks were counted relatively accurately by flying concentric circles above them. The authors concluded that despite certain limitations related to weather conditions and vegetation cover, infrared thermography may be a useful wildlife population survey tool. One of such weaknesses is the fact that the extent of measurement error cannot be reliably estimated in surveys because the ratio of the number of identified individuals to the actual population of the examined species in a given area remains unknown. In a study by Kissell and Tappe (2004), people who assumed a reclined or horizontal position to simulate resting animals were used as surrogates for whitetailed deer, which was possible due to similarities in the size and thermal profiles of both species. Four of the 20 people participating in the study were located in water (none of them were detected by infrared thermography) and 16 on dry land (only one person was not detected). Infrared thermography was found to be an effective method of detecting animals in lowland deciduous forests, under dry conditions, since water and high moisture hindered the analysis. Mayle et al. (1999) relied on thermographic methods to observe deer in their natural habitat and to estimate distance. According to the above authors, thermal imaging supported determinations of the animals' sex and age during the antler growing period; nonetheless, they found this method to be relatively ineffective in densely overgrown areas.

Thermal imaging tools are used to spot newborn deer calves which are naturally left hidden in the undergrowth. For this reason, estimations of population size and detection of individuals for treatment purposes may be difficult in deer farms and research sites in the natural habitat. Ditchkoff et al. (2005) evaluated the suitability of thermal imaging technology for capturing white-tailed deer fawns. The authors monitored the study area at night, from a slow-moving truck. They demonstrated that infrared thermography was equally or more efficient than other reported methods for capturing neonatal fawns. Capture efficiency was lower in areas with thick vegetation. Some of the located thermally active spots were found to be other animals or "heat signatures," i.e., places where animals had recently rested. According to the cited authors, the tested thermal imaging system is relatively cheap, and the analysis can be performed relatively rapidly, compared with other techniques. Butler et al. (2006) conducted a similar study in semiarid shrub communities in Texas, USA, and detected only one white-tailed deer fawn with the use of a thermal infrared camera. According to the authors, it may be impossible to find fawns hidden in dense vegetation by IRT, and direct sunlight in the habitat can lead to false signals. Thus, wildlife researchers should consider vegetation cover, animal population densities, and road quality in a given area before purchasing expensive thermal imaging equipment. 
Research studies are undertaken to investigate the effectiveness of thermography in the search of animals and their hiding places which are difficult to detect with the use of conventional methods. Boonstra et al. (1994) used farinfrared thermal imaging devices to detect small mammals and their nests or burrows. The study was conducted under natural conditions, in the spring and winter seasons, and it involved four animal species: the American red squirrel (Tamiasciurus hudsonicus), the Arctic ground squirrel (Spermophilus parryii), the snowshoe hare (Lepus americanus), and the meadow jumping mouse (Zapus hudsonicus). The presence of red squirrels, snowshoe hares, and meadow jumping mice, and the activity at nests or burrows of Arctic ground squirrels were successfully detected with the use of infrared thermal imaging. However, the technique was not useful in detecting the active nests of red squirrels, due to their insulative properties. The authors found that Arctic ground squirrels live in burrow systems with several entrances and suggested that the "hottest" entrance was a natural vent for the entire system. The authors also observed that thermal imaging devices were most useful when vegetation cover was minimal. Boonstra et al. (1995) examined also the utility of far-infrared (FIR) thermal imaging devices to detect various bird species and their nests. The following bird species were studied: four species of cavity-nesting birds: the pileated woodpecker (Dryocopus pileatus), the northern flicker (Colaptes auratus), Barrow's goldeneye (Bucephala islandica), and the bufflehead (Bucephala albeola); two species of ground-nesting waterfowl: the mallard (Anas platyrhynchos) and the green-winged teal (Anas crecca); the great-horned owl (Bubo virginianus); and two Arctic tundra species: the Lapland longspur (Calcarius lapponicus) and the pectoral sandpiper (Calidris melanotos). Thermal imaging was successful in detecting the active nests of all four cavity-nesting species and the nests of Arctic tundra birds, provided that their approximate location was known. However, the technique was not useful for detecting the active nests and individuals of mallards and green-winged teals, and resting great-horned owls. The location of Arctic tundra birds was successfully detected by FIR imaging. According to the cited authors, the differences in IRT efficiency in locating birds and their nests resulted from variations among bird species in the insulative properties of their feathers and nests. They concluded that FIR imaging is a useful tool for detecting the occupied nests of cavity- and burrow-nesting birds, and for determining the activity of birds in open habitats.

Thermal imaging is a highly promising tool in studies of nocturnal animals because other survey techniques have numerous limitations. Sabol and Hudson (1995) estimated the population size of the gray bat (Myotis grisescens) using thermal infrared imaging and tested a semiautomated system for counting bats during nocturnal emergence. In their work described in the subsection "Analyses of animal behavior," Hristov et al. (2008) demonstrated that thermal imaging combined with IT and engineering techniques is a valuable tool for monitoring bat populations, including direct counts.

Thermal imaging has also been used for the observation and counting of large sea mammals. In a study by Perryman et al. (1999), eastern Pacific gray whales (Eschrichtius robustus) were detected based on their blows recorded using thermal imaging sensors. The data were analyzed to determine the migration rate and swimming speed of gray whales and diel variation in migration rates. It was found that the nocturnal migration rate was higher than the diurnal rate.

\section{Limitations}

The examples of practical applications presented in the preceding chapter clearly indicate that thermography is a rapidly growing technique that creates vast opportunities for wildlife research. Despite the above, the discussed technique has certain limitations which result from external factors, animal behavior, or hardware imperfections. Below is an overview of the possible limitations of thermography and the solutions applied to minimize the resulting errors.

1. Weather conditions-factors such as solar radiation, precipitation, wind, and air humidity significantly affect measurement results. Sunlight heats the surface of the skin (the intensity of solar heating is determined by the color of the coat), thus preventing reliable analysis of internal body temperature. Solar radiation heats the ground and other environmental features which could produce erratic results in animal surveys and population counts (Boonstra et al. 1995; Garner et al. 1995; Hellebrand et al. 2003; Ditchkoff et al. 2005; Butler et al. 2006; McCafferty 2007; Hilsberg-Merz 2008). Rainfall cools the surface of animal bodies and objects, which also contributes to measurement errors (Kissell and Tappe 2004; Boonstra et al. 1994). Intensive air movement cools the surface of the body and disrupts measurements of dissipated heat. Atmospheric gasses (water vapor) and particles (dust, snow) lower atmospheric permeability, leading to the absorption (gasses) or dissipation (particles) of infrared radiation emitted by objects (Minkina 2004). For this reason, air humidity, fog, snow, and dust can significantly distort the results of thermographic analyses. If thermal imaging cameras are used indoors, the examined environment should be free of radiation sources such as windows or heaters as well as devices that cause air movement (windows, fans, air-conditioners). Field experiments should be performed at night or shortly before dawn. Thermograms obtained before sunrise eliminate errors which result from animal movement (running, resting) 
(refer to point 6). During day time, thermographic surveys produce the most accurate results in overcast weather. The greater the difference between the temperature of the animal and its surroundings, the more accurate the survey, which is why thermographic analyses are most effective at night or dawn (Butler et al. 2006; Ditchkoff et al. 2005).

2. Distance between the object and the thermal imaging camera - temperature distribution on the surface of an animal's body can be measured accurately only from a distance of several meters when the measurement error caused by limited atmospheric transmission (permeability) and infrared radiation from the object is minimal (Minkina 2004). In studies of captive animals, thermal images should be acquired at identical distances from the analyzed object.

3. Field of view - the field of view of a thermal imaging camera determines the size of the surveyed area, which implies different exposure to solar radiation. To eliminate this error, thermal measurements should be performed with a field of view of $90^{\circ}$ to max. $50^{\circ}$ (Minkina 2004).

4. Plants and other objects between the analyzed object and a thermal imaging camera affect measurement results. Thick vegetation and dense nesting cover conceal the animal, making it invisible to the camera (Boonstra et al. 1994, 1995; Garner et al. 1995; Kissell and Tappe 2004; Ditchkoff et al. 2005; Butler et al. 2006). Areas with sparse and low vegetation (coastlines, fields) offer the ideal environment for thermographic studies.

5. Physical properties of the animal coat - the thickness and quality of a hair coat or a feather coat significantly affect the temperature on the outer surface of the body. Animals with a thick fur coat, such as sheep and llamas, are weakly visible in thermograms, whereas elephants and rhinoceros whose skin is barely covered with hair are the ideal models for thermal imaging studies (Hilsberg-Merz 2008). Skin temperature registered by infrared cameras is also affected by the thickness of subcutaneous fat which insulates the body against heat loss. Skin contamination, skin cuts, moisture (Kastelic et al. 1996; Kunc et al. 2007; Hilsberg-Merz 2008; Bowers et al. 2009) and color of the coat (Hellebrand et al. 2003; McCafferty 2007) also influence the accuracy of thermographic results. If possible, the skin should be cleaned and left to dry before measurement to eliminate possible errors.

6. Physical activity - physical activity before measurement (running, training) causes heat to be dissipated by skeletal muscles which increases the temperature of the outer body surfaces (Hilsberg 1998; Jodkowska 2005; Hilsberg-Merz 2008). Resting position may also affect the registered temperature - cooler areas will be visualized in a thermogram of an animal resting on its side on cool or moist ground. To minimize the possibility of error, animals should not perform physical activity and should be kept in experimental premises before measurement.

7. Stressors - an animal's thermal profile is affected by stress (Hilsberg 1998; Nakayama et al. 2005; Stewart et al. 2005). For this reason, thermographic analyses should be performed in quiet surroundings after the animal has adjusted to its environment and the examiner.

8. Blood circulation - pharmacological agents with local or systemic effects on the circulatory system lead to changes in surface body temperature. The use of body covers, such as bandages, wraps, blankets, or saddles also affects the temperature of the corresponding body parts.

9. Animal behavior - the response of animals, in particular wild animal species, to changing environmental factors cannot be predicted. Persons performing thermographic measurements are unable to control the outcome of thermographic measurements involving wild animals.

10. Cost - thermal imaging devices continue to be expensive.

\section{Discussion and conclusions}

Observations and studies of wild animals are fraught with many problems due to the unique biological and behavioral traits of different species, such as nocturnal lifestyle, concealed hideouts, protective coloration, and high vigilance levels. In wildlife surveys, thermal imaging tools support the acquisition of results that cannot be obtained by any other method, and they contribute to the improvement of other analytical methods. Despite several limitations, thermography can be expected to enter mainstream use as advances are made in other areas of science, including information technology, engineering, and graphic design. The versatility of thermal imaging applications, the ease of measurement, and the relevance of the produced results will undoubtedly make thermography a leading tool in wildlife surveys in the future.

Acknowledgments The authors wish to thank the management of the Research Station of the Institute of Parasitology, Polish Academy of Sciences, branch in Kosewo Górne, for the opportunity to conduct research in the field of thermal imaging and related areas.

Open Access This article is distributed under the terms of the Creative Commons Attribution License which permits any use, distribution, and reproduction in any medium, provided the original author(s) and the source are credited.

\section{References}

Arenas A, Gomez F, Salas R, Carrasco P, Borge C, Maldonado A, O'Brien D, Martinez-Moreno FJ (2002) An evaluation of the application of infrared thermal imaging to the tele-diagnosis of sarcoptic mange in the Spanish ibex (Capra pyrenaica). Vet Parasitol 109:111-117 
Boonstra R, Krebs CJ, Boutin S, Eadie JM (1994) Finding mammals using far-infrared thermal imaging. J Mammal 75(4):1063-1068

Boonstra R, Eadie JM, Krebs CJ, Boutin S (1995) Limitations of far infrared thermal imaging in locating birds. J Field Ornithol 66 (2): 192-198

Bowers S, Gandy S, Anderson B, Ryan P, Willard S (2009) Assessment of pregnancy in the late-gestation mare digital infrared thermography. Theriogenology 72:372-377

Butler DA, Ballard WB, Haskell SP, Wallace MC (2006) Limitations of thermal infrared imaging for locating naonatal deer in semiarid shrub communities. Wildl Soc Bull 34(5):1458-1462

Collier BA, Ditchkoff SS, Raglin JB, Smith JM (2007) Detection probability and sources of variation in white-tailed deer spotlight surveys. J Wildl Manag 71(1):277-281

Ditchkoff SS, Raglin JB, Smith JM, Collier BA (2005) From the field: capture of white-tailed deer fawns using thermal imaging technology. Wildl Soc Bull 33(3):1164-1168

Dunbar MR, MacCarthy KA (2006) Use of infrared thermography to detect sings of rabies infection in raccoons (Procyon lotor). J Zoo Wildl Med 37(4):518-523

Dunbar MR, Johnson SR, Ryan JC, McCollum M (2009) Use of infrared thermography to detect thermographic changes in mule deer (Odocoileus hemionus) experimentally infected with footand-mouth disease. J Zoo Wildl Med 40(2):296-301

Durrant BS, Ravida N, Spady T, Cheng A (2006) New technologies for the study of carnivore reproduction. Theriogenology 66:17291736

Garner DL, Underwood HB, Porter WF (1995) Use of modern infrared thermography for wildlife population surveys. Environ Manag 19 (2):233-238

Graves HB, Bellis ED, Knuth WM (1972) Censusing white-tailed deer by airborne thermal infrared imagery. J Wildl Manag 36:875-884

Hellebrand HJ, Brehme U, Beuche H, Stollberg U, Jacobs H (2003) Application of thermal imaging for cattle management. Proc., 1st European Conference on Precision Livestock Farming, Berlin, Germany, pp 761-763

Hilsberg S (1998) Infrared-thermography in zoo animals: new experiences with this method, its use in pregnancy and inflammation diagnosis and survey of environmental influences and thermoregulation in zoo animals. European Association of Zoo- and Wildlife Veterinarians (EAZWV), Chester, Second scientific meeting, May 21-24

Hilsberg-Merz S (2008) Infrared thermography in zoo and wild animals. In: Flower ME, Eric Miller R (eds) Zoo and wild animal medicine current therapy, volume six. Saunders, Elsevier, St. Louis, pp 20-33

Hodnett E (2005) Thermal imaging applications in urban deer control. Nolte DL, Fagerstone KA (eds) Proceedings of the $11^{\text {th }}$ Wildlife damage Management Conference. pp 141-148

Hristov NI, Betke M, Kunz TH (2008) Applications of thermal infrared imaging for research in aeroecology. Integr Comp Biol 48(1):50 59

Jodkowska E (2005) Temperatura powierzchni ciała jako kryterium predyspozycji wysiłkowych konia. Dissertation, University of Environmental Life and Sciences in Wrocław

Kastberger G, Stachl R (2003) Infrared imaging technology and biological applications. Behav Res Methods Instum Comput 35(3):429-439
Kastelic JP, Cook RB, Coulter GH, Wallins GL, Entz T (1996) Environmental factors affecting measurement of bovine scrotal surface temperature with infrared thermography. Anim Reprod Sci 41:153-159

Kissell RE Jr, Tappe PA (2004) An assessment of thermal infrared detection rates using white-tailed deer surrogates. J Arkansas Acad Sci 58:70-73

Klir JJ, Heath JE, Bennani N (1990) An infrared thermographic study of surface temperature in relation to external thermal stress in the Mongolian gerbil, Meriones unguiculatus. Comp Biochem Physiol A 96(1):141-146

Knizkova I, Kunc P, Gurdil GAK, Pinar Y, Selvi KC (2007) Applications of infrared thermography in animal production. J Fac Agric OMU 22(3):329-336

Kuhn RA, Meyer W (2009) Infrared thermography of the body surface in the Eurasian otter Lutra lutra and the giant otter Pteronura brasiliensis. Aquat Biol 6:143-152

Kunc P, Knizkova I, Prikryl M, Maloun J (2007) Infrared thermography as a tool to study the milking process: a review. Agric Trop Subtrop 40(1):29-32

Lancaster WC, Thomson SC, Speakman JR (1997) Wing temperature in flying bats measured by infrared thermography. J Therm Biol 2:109-116

Lavers C, Franks K, Floyd M, Plowman A (2005) Application of remote thermal imaging and night vision technology to improve endangered wildlife resource management with minimal animal distress and hazard to humans. J Phys Conf Ser 15:2007-2012

Mayle BA, Peace AJ, Gill RMA (1999) How many deer? A field guide to estimating deer population size. The Forestry Commission, Edinburgh

McCafferty DJ (2007) The value of infrared thermography for research on mammals: previous applications and future directions. Mammal Rev 37(3):207-223

McCafferty DJ, Moncrieff JB, Taylor IR, Boddie GF (1998) The use of IR thermography to measure the radiative temperature and heat loss of a barn owl (Tyto alba). J Therm Biol 23(5):311-318

Minkina W (2004) Pomiary termowizyjne-przyrzady i metody. Wydawnictwa Politechniki Częstochowskiej, Częstochowa

Nakayama K, Goto S, Kuraoka K, Nakamura K (2005) Decrease in nasal temperature of rhesus monkeys (Macaca mulatta) in negative emotional state. Physiol Behav 84:783-790

Perryman WL, Donahue MA, Laake JL, Martin TE (1999) Diel variation in migration rates of eastern pacific gray whales measured with thermal imaging sensors. Mar Mammal Sci 15(2):426-445

Sabol BM, Hudson MK (1995) Technique using thermal infraredimaging for estimating populations of gray bats. J Mammal 76 (4): $1242-1248$

Speakman JR, Ward S (1998) Infrared thermography: principles and applications. Zoology 101:224-232

Stewart M, Webster JR, Schaefer AL, Cook NJ, Scott SL (2005) Infrared thermography as a non-invasive tool to study animal welfare. Anim Welf 14:319-325

Sumbera R, Zelova J, Kunc P, Knizkova I, Burda H (2007) Patterns of surface temperatures in two male-rats (Bathyergidae) with different social system as revealed by IR-thermography. Physiol Behav 92(3):526-532

Tattersal GJ, Cadena V (2010) Insight into animal temperature adaptations revealed through thermal imaging. Imaging Sci J $58: 281-286$ 